\title{
Graph-Analytical Method of Determining Impedance in Electrical Transformers
}

\author{
Zorica Bogicevic, ${ }^{1}$ Slobodan Bjelić, ${ }^{2}$ Petar Spalević, ${ }^{2}$ and Milan Mišićc ${ }^{1}$ \\ ${ }^{1}$ Higher Technical Professional School in Zvečan, Nušićeva 6, 38227 Zvečan, Serbia \\ ${ }^{2}$ Faculty of Technical Sciences, University of Priština, Kneza Miloša 7, 38220 Kosovska Mitrovica, Serbia
}

Correspondence should be addressed to Zorica Bogicevic; zocabogi@gmail.com and Slobodan Bjelić; slobodanbjelic49@yahoo.com

Received 11 June 2015; Accepted 6 September 2015

Academic Editor: Hou-Sheng Su

Copyright (C) 2015 Zorica Bogicevic et al. This is an open access article distributed under the Creative Commons Attribution License, which permits unrestricted use, distribution, and reproduction in any medium, provided the original work is properly cited.

\begin{abstract}
This paper presents a graph-analytical method for determining the electrical impedance of alternate energy sources, especially small power transformers and current transformers in electric networks. Unlike conventional short-circuit and idle tests, according to proposed method, in this paper, transformer parameters are determined in a new way, which is based on measurement of voltages and currents on the active and reactive load (inductive or capacitive). The effectiveness of the proposed model was verified using an adapted simulation in the software package MATLAB Simulink. The simulation was performed for three types of ABB transformers with a $100 \%$ load. Simulation results were obtained for power transformers: $S_{n 1}=1$ [MVA], $S_{n 2}=2$ [MVA], $S_{n 3}=3.15$ [MVA]. If we compare measurement result values of $R_{T}, X_{T}$, which are contained in a brochure for ABB transformers and those obtained through simulation, different tolerances are obtained. For reactance results, deviations are up to $20 \%$ for all three tested transformers. For results of active resistance tolerances are up to $5 \%$ for all three tested transformers. This method can be used not only to determine the active and inductive AC power source parameters but also to determine and analyze the impendence of electrical sources with high frequencies.
\end{abstract}

\section{Introduction}

In addition to classical methods, one of the possible methods for obtaining the values and parameters of the transformer is graph-analytical method based on the construction of phase diagrams for different types of transformer loads.

Three-phase two-coiled transformer (Figure 1(a)) has $\mathrm{HV} / \mathrm{LV}$ coils in coupling Dy11 (or Yy11) [1]. In the delta or star coupling HV transformers' coils, phase voltages have a sinusoidal shape and the same form of voltage that has the network from which the transformer is supplied. In symmetrical regime, the analysis of three-phase transformers is reduced to the analysis of the schemes of equivalent single-phase transformers. Equivalent single-phase diagram gives a picture of the three-phase system only if the system in all three phases has equal impedances $Z$, through the same modules flow as the same voltage modules $V$ act on impedance. Single-phase transformer with two windings corresponds to equations where secondary values are reduced to the primary side (Figure 1(f)) [1]:

$$
\begin{aligned}
\dot{V}^{\prime} & =-\dot{E}^{\prime}+Z^{\prime} \dot{I}^{\prime}, \\
-\dot{E}^{\prime} & =-\dot{E}_{1}^{\prime \prime}=Z_{0} \dot{I}_{0}=Z_{\mu} \dot{I}_{\mu} .
\end{aligned}
$$

The electrical circuit secondary values must be expressed in a way that the primary voltage refers to the primary current. At the beginning the current $\dot{I}^{\prime}$ must be determined in relation to ems $\dot{E}^{\prime}$ and to the parameters of the circuit:

$$
\begin{aligned}
\dot{I}^{\prime} & =\dot{I}_{0}-\dot{I}_{1}^{\prime \prime}=-\frac{\dot{E}}{Z_{0}}+\frac{-\dot{E}^{\prime}}{Z_{1}^{\prime \prime}+Z_{1 \text { load }}^{\prime \prime}}, \\
-\dot{E}^{\prime} & =\frac{\dot{I}^{\prime}}{1 / Z_{0}+1 /\left(Z_{1}^{\prime \prime}+Z_{1 \text { load }}^{\prime \prime}\right)} .
\end{aligned}
$$




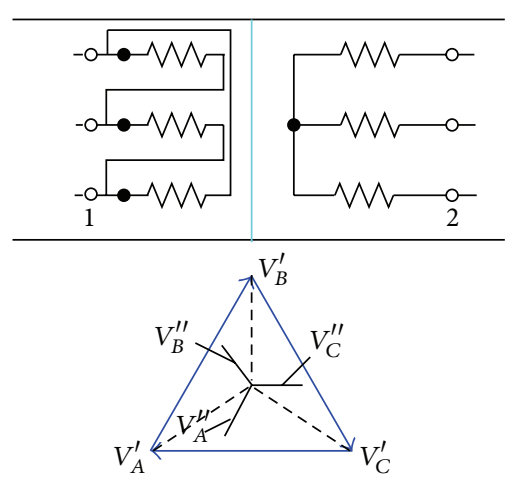

(a) $D y_{n} 11$-grope
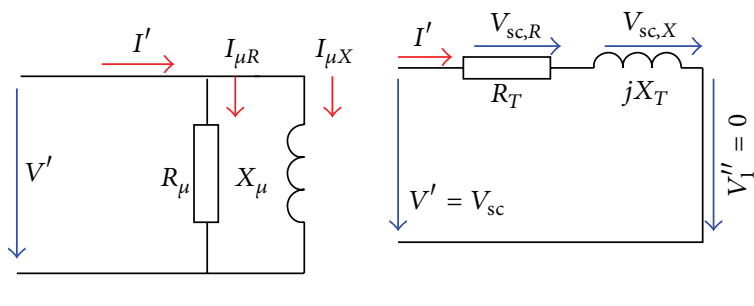

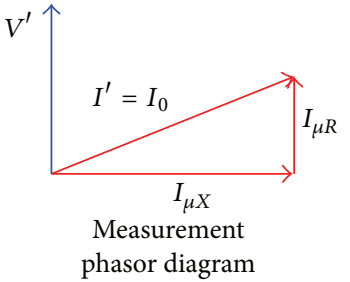

(b) No-load

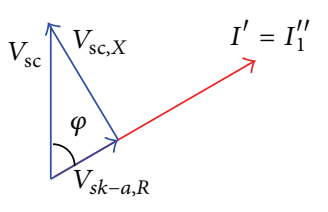

Measurement phasor diagram

(c) Short-circuit
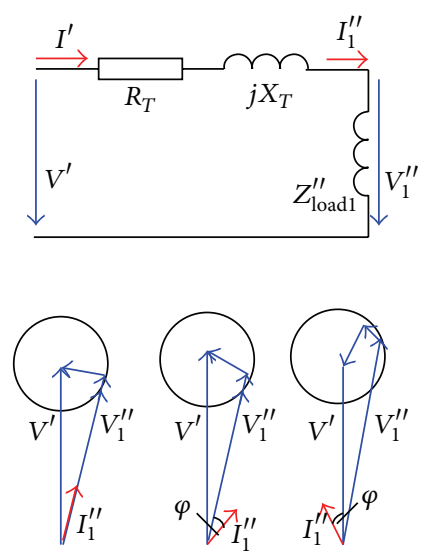

$V^{\prime \prime}$ depends on $I^{\prime \prime}$ and $\varphi$ on all transformers phasor diagram

(d) Loads $R, X_{L}, X_{C}$

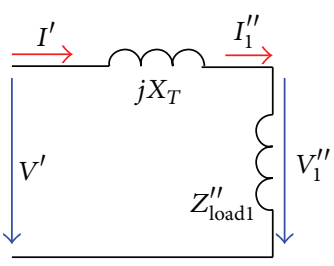

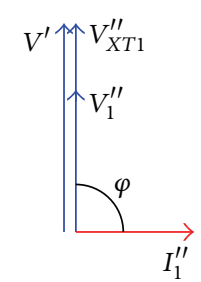

(e) High frequencies

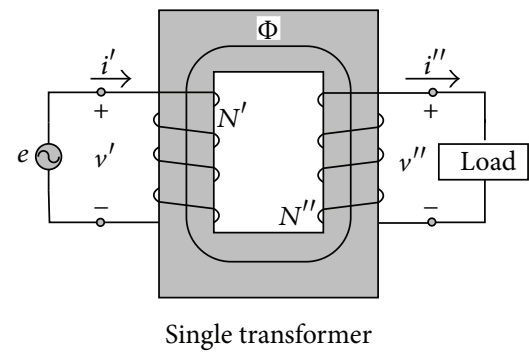

(f)

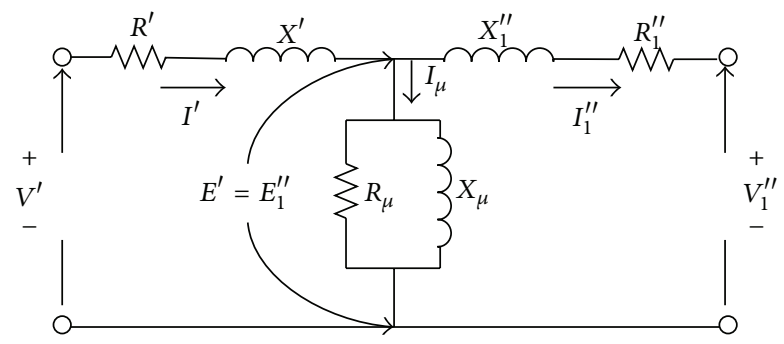

Equivalent circuit of transformer

(g)

FIGURE 1: Measurement graph-analytical transformer model for (a) Dy11 grope, (b) no-load, (c) short-circuit, (d) load, (e) high frequencies, (f) single load transformer, (g) and equivalent circuit of transformer.

By replacing the previous dependencies into the voltage equation $\dot{V}^{\prime}=-\dot{E}^{\prime}+Z^{\prime} \dot{I}^{\prime}$ the following is obtained:

$$
\begin{aligned}
& \dot{V}^{\prime}=\dot{I}\left[Z^{\prime}+\frac{1}{1 / Z_{0}+1 /\left(Z_{1}^{\prime \prime}+Z_{1 \text { load }}^{\prime \prime}\right)}\right]=\dot{I}^{\prime} Z_{\text {eq }} \\
& Z_{\text {eq }}=Z^{\prime}+\frac{1}{1 / Z_{0}+1 /\left(Z_{1}^{\prime \prime}+Z_{1 \text { load }}^{\prime \prime}\right)} .
\end{aligned}
$$

From relation (4) it is clear that equivalent circuit of the transformer, where the primary current $I^{\prime}$ passes, must have equivalent impedance $Z_{\mathrm{eq}}$. This impedance is presented in the circuit and is described in Figure 1, where the series connection $Z^{\prime}$ with the parallel combination $Z_{0}=Z_{\mu}$ and $\left(Z_{1}^{\prime \prime}+Z_{1 \text { load }}^{\prime \prime}\right)$ is shown and parameters of transformers, which are included with losses, are in classical-conventional manner measured in the experiment of idling (no-load) 
and in the short-circuit test. For small power transformers, due to difficulties in measuring active losses this method is practically not applicable.

A classic method (Section 2) and the proposed-analytical method (Section 3) are shown in this paper. The model proposed in this paper is verified by simulation in MATLAB Simulink software package (Section 4). In the adapted simulation model for three different $\mathrm{ABB}$ transformers of low power, tabular and graphical results are obtained (Section 5).

\section{Measurement of Transformer's Impedance}

2.1. The Short-Circuit Test. The equations of transformer when it is not loaded (Figure 1(b)), for defined primary impedance $Z^{\prime}$, can be formulated on the basis of the general system of $[1,2]$

$$
\begin{aligned}
\dot{V}^{\prime} & =-\dot{E}^{\prime}+Z^{\prime} \dot{I}^{\prime}, \\
\dot{V}^{\prime \prime} & =\dot{E}^{\prime \prime}-Z^{\prime \prime} \dot{I}^{\prime \prime} \\
& \Longrightarrow \dot{V}_{1}^{\prime \prime}=\dot{E}^{\prime \prime}-Z_{1}^{\prime \prime} \dot{I}_{1}^{\prime \prime}, \quad \dot{I}^{\prime}=\dot{I}_{0}-\dot{I}_{1}^{\prime \prime} .
\end{aligned}
$$

If the impedance load is great $\left(Z_{\text {load }} \rightarrow \infty\right)$, the value of secondary current is equal to zero:

$$
\begin{aligned}
& I^{\prime \prime}=0, \\
& \dot{I}_{1}^{\prime \prime}=0, \\
& \dot{V}^{\prime}=-\dot{E}^{\prime}+Z^{\prime} \dot{I}^{\prime}=\dot{I}^{\prime}\left(Z^{\prime}+Z_{0}\right), \\
& \dot{V}_{1}^{\prime \prime}=-\dot{E}_{1}^{\prime \prime}=-\dot{E}^{\prime}=Z_{0} \dot{I}_{0}, \\
& \dot{I}^{\prime}=\dot{I}_{0} .
\end{aligned}
$$

The medium values of phase currents and medium voltage values are obtained by three-phase transformer in idling current:

$$
\begin{gathered}
\dot{I}_{0}=\frac{\left(I_{A}+I_{B}+I_{C}\right)}{3}, \\
\dot{V}^{\prime}=\frac{\left(V_{A}+V_{B}+V_{C}\right)}{3} .
\end{gathered}
$$

Based on the values $I_{0} i V^{\prime} i$ researcher can determine idling power factor $\left(\cos \varphi_{0}\right)$. The sizes of the transformer which can be determined from experiments of idling at rated voltage are as follows.

Transmission ratio of the transformer, which is the ratio of secondary and primary rated voltage at idle, is as follows:

$$
K_{n}=\frac{N^{\prime \prime}}{N^{\prime}}=\frac{E_{R}^{\prime \prime}}{E_{R}^{\prime}} \approx \frac{V_{R}^{\prime \prime}}{V_{R}^{\prime}} .
$$

Idle current $I_{0, o c}$, idle current and its relative value, as a part of rated primary current in p.u. system, are as follows:

$$
\dot{I}_{0, \mathrm{oc}, \mathrm{pu}}=\frac{I_{0, \mathrm{oc}}}{I_{R}^{\prime}} .
$$

The mutual impedance, defined when $Z^{\prime} \approx 0$, is as follows:

$$
\left|Z_{0}\right| \approx \frac{V_{R}^{\prime}}{I_{0, \mathrm{oc}}}=\left|Z_{0, \mathrm{oc}}\right| .
$$

Its active component is obtained as

$$
R_{0}=\frac{P_{0, \mathrm{oc}}}{3 I_{0, \mathrm{oc}}^{2}}=\left|Z_{0}\right| \cos \varphi_{0}
$$

and reactive component-reactance is obtained as

$$
X_{0}=\sqrt{Z_{0}^{2}-R_{0}^{2}}=\left|Z_{0}\right| \sin \varphi_{0} \approx\left|Z_{0}\right| \text {. }
$$

2.2. Losses in Idling. When the voltage is equal to the nominal $V^{\prime}=V_{R}^{\prime}$ practically do not differ from losses in the magnetic circuit (core), $P_{\text {core,oc }}$, because the losses at primer's copper, $P_{\mathrm{Cu}, \mathrm{oc}}^{\prime}=3 I_{0, \mathrm{oc}}^{2} R^{\prime}$, in those conditions are small, since the current $I_{0, o c}$ has low value. The magnetization characteristic of any magnetic circuit made by ferromagnetic material contains information about the useful flux saturation degree $[3,4]$. In the paper magnetic has value of residual flux since there is no load (provided that it is $V^{\prime}$ predominantly unchanged) $[5,6]$. However, at rated voltage, the losses in the core $P_{\text {core }}$ are about the same as losses at idle, $P_{\text {core,oc, }}$, that is, total idle losses: $P_{o, \text { oc }}, P_{\text {core }}=P_{\text {core.oc }}=P_{0}$. Dangerous transient currents of the transformer can occur if a shortcircuit on the secondary side happened at rated voltage $V^{\prime}=$ $V_{R}^{\prime}[7]$.

2.3. The Short-Circuit Test. Secondary side of transformer is short-circuited ( Figure 1(c)) [2] and then the value of the impedance load $\left(Z_{1 \text { load }}^{\prime \prime} \approx 0\right)$ and secondary voltage $V_{1}^{\prime \prime} \approx$ 0 are also equal to zero (in a three-phase transformer, all secondary ends are short-circuited to obtain a balanced short circuit). The equations for the transformer for short-circuit experiment are derived from the general system of

$$
\begin{gathered}
\dot{V}^{\prime}=-\dot{E}^{\prime}+Z^{\prime} \dot{I}^{\prime} \\
-\dot{E}^{\prime}=-\dot{E}_{1}^{\prime \prime}=-Z_{1}^{\prime \prime} \dot{I}_{1}^{\prime \prime}=Z_{0} \dot{I}_{0}=Z_{\mu} \dot{I}_{\mu}, \\
\left(Z_{0}=\infty \Longleftrightarrow \dot{I}_{0}=0\right), \quad \dot{I}^{\prime}=\dot{I}_{0}-\dot{I}_{1}^{\prime \prime} .
\end{gathered}
$$

Application of that system of equations on the equivalent circuit in Figure $1(\mathrm{~g})[1,2]$ for short-circuit scheme can be determined by primary $I^{\prime}$ and secondary $-I_{1}^{\prime \prime}$ current, magnetizing current $I_{0}$ and the common ems short-circuit $-E^{\prime}$. One has

$$
\begin{aligned}
\dot{I}^{\prime} & =\frac{\dot{V}^{\prime}}{Z^{\prime}+Z_{1}^{\prime \prime} Z_{0} /\left(Z_{1}^{\prime \prime}+Z_{0}^{\prime \prime}\right)}=\frac{\dot{V}^{\prime}}{Z_{\mathrm{sc}}} \approx \frac{\dot{V}^{\prime}}{Z^{\prime}+Z_{1}^{\prime \prime}}, \\
-\dot{I}_{1}^{\prime \prime} & =\frac{\dot{I}^{\prime} Z_{0}}{Z_{1}^{\prime \prime}+Z_{0}} \approx \dot{I}^{\prime},
\end{aligned}
$$




$$
\begin{aligned}
\dot{I}_{0} & =\dot{I}^{\prime} \frac{Z_{1}^{\prime \prime}}{Z_{1}^{\prime \prime}+Z_{0}} \approx \frac{\dot{V}^{\prime}}{Z_{0}} \frac{Z_{1}^{\prime \prime}}{Z_{\mathrm{sc}}}=\dot{I}_{0, \mathrm{oc}} \frac{Z_{1}^{\prime \prime}}{Z_{\mathrm{sc}}} \\
-\dot{E}^{\prime} & =Z_{0} \dot{I}_{0}=Z_{0} \dot{I}_{0, \mathrm{oc}} \frac{Z_{1}^{\prime \prime}}{Z_{\mathrm{sc}}}=\dot{V}^{\prime} \frac{Z_{1}^{\prime \prime}}{Z_{\mathrm{sc}}}
\end{aligned}
$$

where

$$
Z_{\mathrm{sc}}=Z^{\prime}+\frac{Z_{1}^{\prime \prime} Z_{0}}{Z_{1}^{\prime \prime}+Z_{0}} \approx Z^{\prime}+Z_{1}^{\prime \prime}
$$

If $Z_{0} \gg Z_{1}^{\prime \prime}$ is impedance, its active resistance and reactance of the transformer are

$$
Z_{\mathrm{sc}} \approx Z^{\prime}+Z_{1}^{\prime \prime}=R_{\mathrm{sc}}+j X_{\mathrm{sc}}=Z_{T}
$$

Impedance of transformer of the short-circuited secondary is reduced on a side of supply-line network.

The corresponding phase diagram is shown in Figures $1(\mathrm{c}), 1(\mathrm{~d})$, and 1(e) [2]. As it is seen from this diagram, shortcircuit voltage $V^{\prime}=V_{\mathrm{sc}}=Z_{\mathrm{sc}} I^{\prime}$ is triangle's hypotenuse and catheters are active voltage $V_{\mathrm{sc}, R}=R_{\mathrm{sc}} I^{\prime}$ and reactive voltage $V_{\mathrm{sc}, R}=j X_{\mathrm{sc}} I^{\prime}$. The angle of voltage $\varphi_{\mathrm{sc}}$ (or impedance, called short-circuit angle) triangle that graphically displays $[8,9]$ the short-circuit conditions is stated as a reference for the short-circuit triangle and is $\varphi_{\mathrm{sc}}=\arctan \left(X_{\mathrm{sc}} / R_{\mathrm{sc}}\right)$. By adjusting $Z^{\prime} \approx Z_{1}^{\prime \prime}=Z_{\mathrm{sc}} / 2$ we will get the simpler expressions for the current magnetizing and short-circuit ems:

$$
\begin{gathered}
\dot{I}^{\prime}=-\dot{I}_{1}^{\prime \prime}=\frac{\dot{V}^{\prime}}{Z_{\mathrm{sc}}}, \\
\dot{I}_{0}=\frac{\dot{V}^{\prime}}{2 Z_{0}}=\frac{I_{0, \mathrm{oc}}}{2}, \\
-\dot{E}^{\prime}=Z_{0} \frac{\dot{I}_{0, \mathrm{oc}}}{2}=\frac{\dot{V}^{\prime}}{2} .
\end{gathered}
$$

Possible equivalent scheme and short-circuit diagram are presented in Figure 1(c). As with experiments of idling it is not necessary to have any particular active load or higher voltage source [10]. If the frequency has a nominal value of $f=f_{\text {RATED }}$, the same values are read as in the experiment of idling, primary current, and power such that a transformer takes $P_{\mathrm{sc}}$.

By reading of values $I^{\prime}, P_{\mathrm{sc}}$, and $\cos \varphi_{\mathrm{sc}}$ which are entered into the diagram as phase voltage functions $V$ a diagram is obtained which is used for graphic determination of $V_{\mathrm{sc}}^{\prime}$, $P_{\mathrm{sc}}$, and $\cos \varphi_{\mathrm{sc}}$ in relation to the primary current values $I^{\prime}=I_{R}^{\prime}$.

Power factor is determined from the values $I^{\prime}$ and $V^{\prime}$ as $\cos \varphi_{\mathrm{sc}}=P_{\mathrm{sc}} / 3 V^{\prime} I^{\prime}$.

Short-circuit test gives the following values of the transformer in relation to rated current values. The impedance of short-circuit and its active and reactive component from the expression is as follows:

$$
\begin{aligned}
\left|Z_{\mathrm{sc}}\right| & =\frac{V_{\mathrm{sc}}^{\prime}}{I_{R}^{\prime}}, \\
R_{\mathrm{sc}} & =\frac{P_{\mathrm{sc}}}{3 I_{R}^{\prime 2}}=\left|Z_{\mathrm{sc}}\right| \cos \varphi_{\mathrm{sc}}, \\
X_{\mathrm{sc}} & =\sqrt{Z_{\mathrm{sc}}^{2}-R_{\mathrm{sc}}^{2}}=\left|Z_{\mathrm{sc}}\right| \sin \varphi_{\mathrm{sc}} .
\end{aligned}
$$

Active component is a sum of resistance of the two coils $R_{\mathrm{sc}}=R^{\prime}+R_{1}^{\prime \prime}=R_{T}$. During short-circuit test, it should be stressed at which temperature $\theta$ the measurement is performed, $R_{\mathrm{sc}}$, where the temperature is set at around $75^{\circ} \mathrm{C}$, where $R_{\mathrm{sc} 75}=R_{\mathrm{sc}}[1+0.004(75-\theta)]$. Reactive component, $X_{\mathrm{sc}}=X^{\prime}+X_{1}^{\prime \prime}=X_{T}$, is calculated from the sum of inductive scattering, independent currents which are flowing through respective coils [11]. From the same reasons $X_{\mathrm{sc}}=X_{T}$ is an independent value in accordance with the tested currents [12]. Impedance and power factor in the short-circuit are set for the temperature of $75^{\circ} \mathrm{C}$ :

$$
\begin{aligned}
\left|Z_{\mathrm{sc}, 75^{\circ} \mathrm{C}}\right| & =\sqrt{R_{\mathrm{sc}, 75}^{2}+X_{\mathrm{sc}, 75}^{2}}, \\
\cos \varphi_{\mathrm{sc}} & =\frac{R_{\mathrm{sc}, 75}}{\left|Z_{\mathrm{sc}, 75}\right|} .
\end{aligned}
$$

2.4. Losses $P_{s c}$ in the Short-Circuit Test. If the rated currents flow through the coils $I^{\prime}=I_{R}^{\prime}=I_{1}^{\prime \prime}$ practically there is no difference in the value of losses in copper on the primary and secondary side:

$$
P_{\mathrm{Cu}, R}=3 R^{\prime} I_{R}^{\prime 2}+3 R_{1}^{\prime \prime} I_{1 R}^{\prime \prime 2}=3 R_{\mathrm{sc}} I_{R}^{\prime 2},
$$

where the copper losses are several times greater than the losses in the core of the transformer at short-circuit, $P_{\text {core,sc }}$.

Short-circuit voltage is defined as the voltage that must lead to single coil, when in the second short-circuited winding rated current $I_{R}^{\prime}$ flows, which corresponds to the nominal voltage of coils at a temperature of $75^{\circ} \mathrm{C}$. If the voltage has been brought to the primary winding, short-circuit voltage is expressed in absolute units $V_{\mathrm{sc}}^{\prime}=\left|Z_{\mathrm{sc}, 75}\right| I_{R}^{\prime}$.

Active and reactive components of short-circuit voltage are obtained by the following expression:

$$
\begin{aligned}
& v_{a, \mathrm{sc}}=\frac{R_{\mathrm{sc}, 75} I_{R}^{\prime}}{V_{R}^{\prime}}=R_{\mathrm{pu}, \mathrm{sc}}=v_{\mathrm{sc}} \cos \varphi_{\mathrm{sc}}, \\
& v_{r, \mathrm{sc}}=\frac{X_{\mathrm{sc}} I_{R}^{\prime}}{V_{R}^{\prime}}=X_{\mathrm{pu}, \mathrm{sc}}=v_{\mathrm{sc}} \sin \varphi_{\mathrm{sc}} .
\end{aligned}
$$

\section{The Proposed Measurement Method}

To determine the two parameters of the impedance sources (in this case resistance $r$ and inductive reactance $x$ transformers), it is sufficient to examine only two modes of load. By graph-analytical method, through analysis of vector 


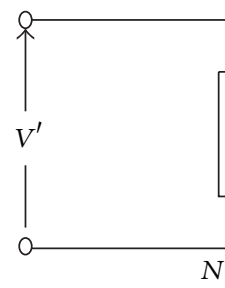

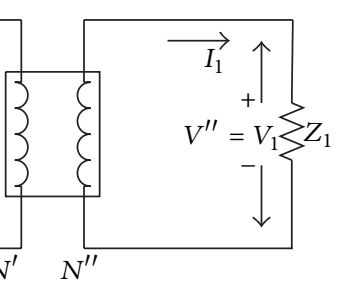

(a) $R$ load

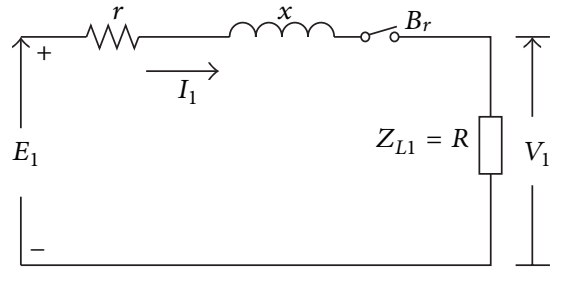

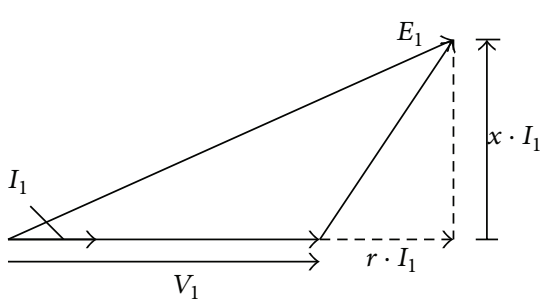

(b) Diagram from $R$ load
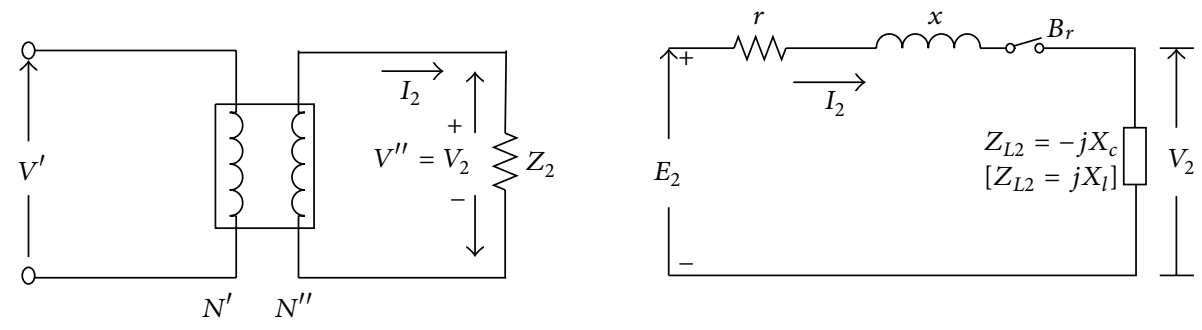

(c) $X_{c}\left[X_{l}\right]$ load

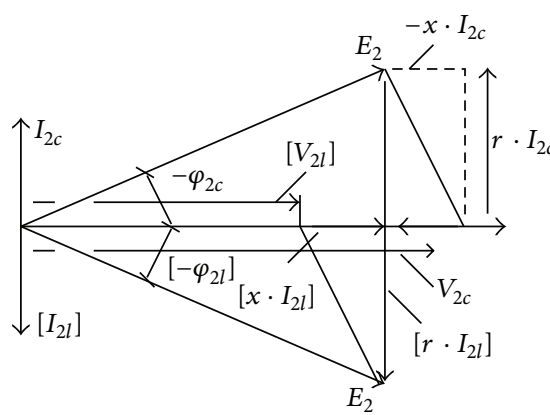

(d) Diagram from $X_{c}\left[X_{l}\right]$ load

FIGURE 2: Scheme and vector diagrams: (a) load $R$-active, (b) vector diagram from $R$ load, (c) reactive $X_{c}\left(X_{l}\right)$ load, and (d) vector diagram for $X_{c}\left(X_{l}\right)$ load.

diagrams of two different passive loads, active and reactive (capacitive/inductive), realistic results can be obtained. It should be emphasized that the application of inductive loads in measurement is not recommended because inductive loads have prominent and active component of resistance that cannot be simply determined (22). The active component of the inductive load also has an impact on the phase stance $\varphi_{2 l}$. Therefore, it is better to perform the procedure with a capacitive load in which the influence of components of active resistance is several times lower. From the vector diagrams that correspond to schemes of measurements (active, Figures 2(a) and 2(b), and reactive capacitive/inductive loads, Figures 2(c) and 2(d) [7]) the equation can be written for the general case:

$$
\begin{aligned}
& R: E_{1}^{2}=\left(V_{1}+r \cdot I_{1}\right)^{2}+x^{2} \cdot I_{1}^{2}, \\
& {\left[\text { sign }:+r I_{1} \Longleftrightarrow R=R, V_{1}=R I_{1} ;|R|=\left|\frac{V_{1}}{I_{1}}\right|\right],} \\
& X_{c}: E_{2}^{2}=\left(V_{2}-x \cdot I_{2}\right)^{2}+r^{2} I_{2}^{2}, \\
& {\left[\text { sign }:-x I_{2} \Longleftrightarrow X=X_{c}=\left|\frac{V_{2}}{I_{2}}\right|, V_{2}=-j X_{c} I_{2}=V_{2 c}\right.} \\
& \left.\quad=-j X_{c} I_{2 c}\right],
\end{aligned}
$$

$$
\begin{aligned}
& X_{l}: E_{2}^{2}=\left(V_{2}+x \cdot I_{2}\right)^{2}+r^{2} \cdot I_{2}^{2}, \\
& {\left[\text { sign }:+x I_{2} \Longleftrightarrow X=X_{l}=\left|\frac{V_{2}}{I_{2}}\right|, V_{2}=j X_{l} I_{2}=V_{2 l}\right.} \\
& \left.\quad=j X_{l} I_{2 l}\right],
\end{aligned}
$$

where $E_{1}, E_{2}$-ems of transformers are in idling (measured or simulated on the secondary side of the transformer when the load is omitted). The solution of (1) and (2) is as follows:

$$
\begin{aligned}
x^{2} \cdot I_{1}^{2}+r^{2} \cdot I_{1}^{2}+r \cdot 2 \cdot V_{1} I_{1} & =E_{1}^{2}-V_{1}^{2}, \\
\left(x^{2}+r^{2}+r \cdot 2 \cdot \frac{V_{1}}{I_{1}}\right) \cdot I_{1}^{2} & =E_{1}^{2}-V_{1}^{2}, \text { act. load, } \\
x^{2} \cdot I_{2}^{2}+r^{2} \cdot I_{2}^{2}-x \cdot 2 \cdot V_{2} I_{2} & =E_{2}^{2}-V_{2}^{2}, \\
\left(x^{2}+r^{2}-x \cdot 2 \cdot \frac{V_{2}}{I_{2}}\right) \cdot I_{2}^{2} & =E_{2}^{2}-V_{2}^{2}, \\
\left(x^{2}+r^{2}-x \cdot 2 \cdot \frac{V_{2}}{I_{2}}\right) & =\frac{E_{2}^{2}}{I_{2}^{2}}-\frac{V_{2}^{2}}{I_{2}^{2}}=N, \text { cap. load, } \\
x^{2} \cdot I_{2}^{2}+r^{2} \cdot I_{2}^{2}+x \cdot 2 \cdot V_{2} I_{2} & =E_{2}^{2}-V_{2}^{2},
\end{aligned}
$$




$$
\begin{aligned}
\left(x^{2}+r^{2}+x \cdot 2 \cdot \frac{V_{2}}{I_{2}}\right) \cdot I_{2}^{2} & =E_{2}^{2}-V_{2}^{2}, \\
\left(x^{2}+r^{2}+x \cdot 2 \cdot \frac{V_{2}}{I_{2}}\right) & =\frac{E_{2}^{2}}{I_{2}^{2}}-\frac{V_{2}^{2}}{I_{2}^{2}}=N, \text { ind. load. }
\end{aligned}
$$

By introducing replacements,

$$
\begin{aligned}
m & =\left(\frac{E_{1}}{I_{1}}\right)^{2}, \\
n & =\left(\frac{E_{2}}{I_{2}}\right)^{2}, \\
R^{2} & =\left(\frac{V_{1}}{I_{1}}\right)^{2}, \\
X_{c}^{2} & =\left(\frac{V_{2}}{I_{2}}\right)^{2}, \\
X_{l}^{2} & =\left(\frac{V_{2}}{I_{2}}\right)^{2} .
\end{aligned}
$$

The following is obtained:

$$
\begin{gathered}
M=m-R^{2}, \\
N=n-X_{c}^{2}, \\
{\left[N=n-X_{l}^{2}\right],} \\
p_{c}=m-n-\left(R^{2}-X_{c}^{2}\right), \\
p_{l}=m-n-\left(R^{2}-X_{l}^{2}\right) .
\end{gathered}
$$

(1) One has $R \& C: x^{2}+r^{2}+r \cdot 2 \cdot R=m-R^{2}$; consider

$$
\begin{gathered}
\frac{x^{2}+r^{2}-x \cdot 2 \cdot X_{c}=n-X_{c}^{2} ;}{2\left(r \cdot R+x \cdot X_{c}\right)=M-N} \\
x=\frac{M-N}{2 X_{c}}-\frac{R}{X_{c}} r, \\
x=\frac{p_{c}}{2 X_{c}}-\frac{R}{X_{c}} r .
\end{gathered}
$$

(2) One has $R \& L: x^{2}+r^{2}+r \cdot 2 \cdot R=m-R^{2}$; consider

$$
\begin{gathered}
\frac{x^{2}+r^{2}+x \cdot 2 \cdot X_{c}=n-X_{l}^{2} ; \angle(-1)}{2\left(r \cdot R-x \cdot X_{l}\right)=M-N} \\
x=-\frac{M-N}{2 X_{l}}+\frac{R}{X_{l}} r, \\
x=-\frac{p_{l}}{2 X_{l}}+\frac{R}{X_{l}} r .
\end{gathered}
$$

To determine the value $r$ in both combinations of $R \& C$ and $R \& L$ first replace the value of the reactance $x$ into (26):

$$
\begin{array}{r}
{\left[\frac{p_{c}}{2 X_{c}}-\frac{R}{X_{c}} r\right]^{2}+r^{2}+2 R \cdot r=M,} \\
{\left[\frac{p_{c}}{2 X_{c}}\right]^{2}-\frac{p_{c}}{X_{c}} \frac{R}{X_{c}} r+\left[\frac{R}{X_{c}}\right]^{2} r^{2}+r^{2}+2 R \cdot r=M,} \\
{\left[-\frac{p_{l}}{2 X_{l}}+\frac{R}{X_{l}} r\right]^{2}+r^{2}+2 R \cdot r=M,} \\
{\left[\frac{p_{l}}{2 X_{l}}\right]^{2}-\frac{p_{l}}{X_{l}} \frac{R}{X_{l}} r+\left[\frac{R}{X_{l}}\right]^{2} r^{2}+r^{2}+2 R \cdot r=M .}
\end{array}
$$

Equitation has the same form for both combinations, so it can be written with parameters $X, p$ :

$$
\left[\frac{p}{2 X}\right]^{2}-\frac{p}{X} \frac{R}{X} r+\left[\frac{R}{X}\right]^{2} r^{2}+r^{2}+2 R \cdot r=M
$$

(explicit relation) or

$$
\left[1+\left(\frac{R}{X}\right)^{2}\right] \cdot r^{2}+\left[2 R-\frac{p R}{X^{2}}\right] \cdot r+\left[\frac{p}{2 X}\right]^{2}-M=0
$$

(implicit relation).

Basic type quadratic equation is obtained: $a r^{2}+b r+c=0$. After replacing values $R / X=q$ coefficients have following values:

$$
\begin{gathered}
a=1+q^{2}, \\
b=R\left[2-\frac{M-N}{X^{2}}\right], \\
c=\left[\frac{M-N}{2 X}\right]^{2}-M \text { or } \\
\left\{b=R\left[2-\frac{p}{X^{2}}\right], c=\left[\frac{p}{2 X}\right]^{2}-M\right\} .
\end{gathered}
$$

Second grade equitation (quadratic) with nominal form $a r^{2}+$ $b r+c=0$ or (after dividing with $(a)): r^{2}+b_{1} r+c_{1}=0$, $\left(b_{1}=b / a\right),\left(c_{1}=c / a\right)$.

The number of real solutions depends on the sign of the discriminant $D$,

$$
D=\left(4 a c-b^{2}\right) \lessgtr 0 \text { or }\left(c_{1}-\frac{b_{1}^{2}}{4}\right) \lessgtr 0,
$$

if one has the following:

(i) $(D<0),\left(4 a c-b^{2}\right)<0$, has 2 solutions (2 real roots).

(ii) $(D=0),\left(4 a c-b^{2}\right)=0$, has 1 solution (2 same roots) $r_{1,2}=-b / 2 a \Leftrightarrow-b / 2 a>0, z a(b<0)$.

(iii) $(D>0),\left(4 a c-b^{2}\right)>0$, has 2 solutions (2 complex roots).

Solving of quadratic equitation, one has the following.

(1) Method: one has

$$
\begin{gathered}
a \cdot r^{2}+b \cdot r+c=a(r-\alpha)(r-\beta)=0 \text { or } \\
r^{2}+b_{1} \cdot r+c_{1}=(r-\alpha)(r-\beta)=0 .
\end{gathered}
$$




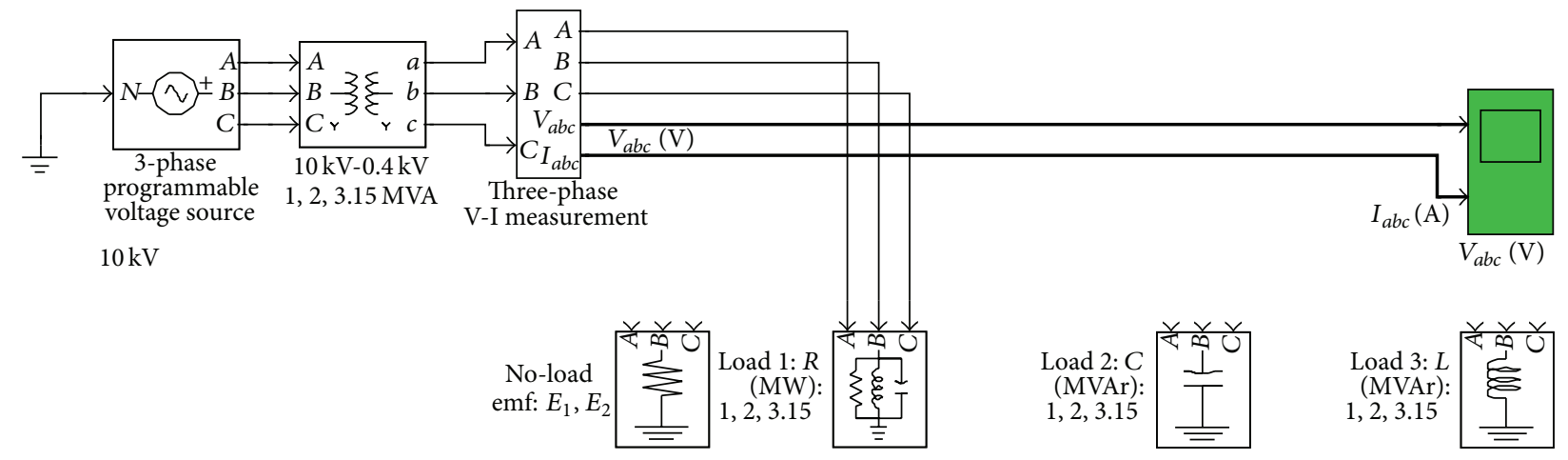

FIGURE 3: Demonstration of the adapted discrete 3-phase programmable voltage source 3-phase V-I measurement.

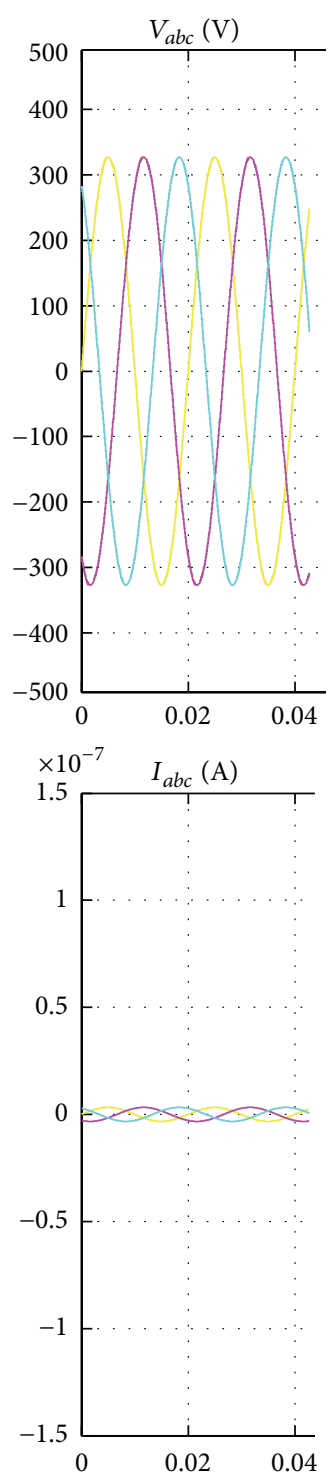

(a) No-load
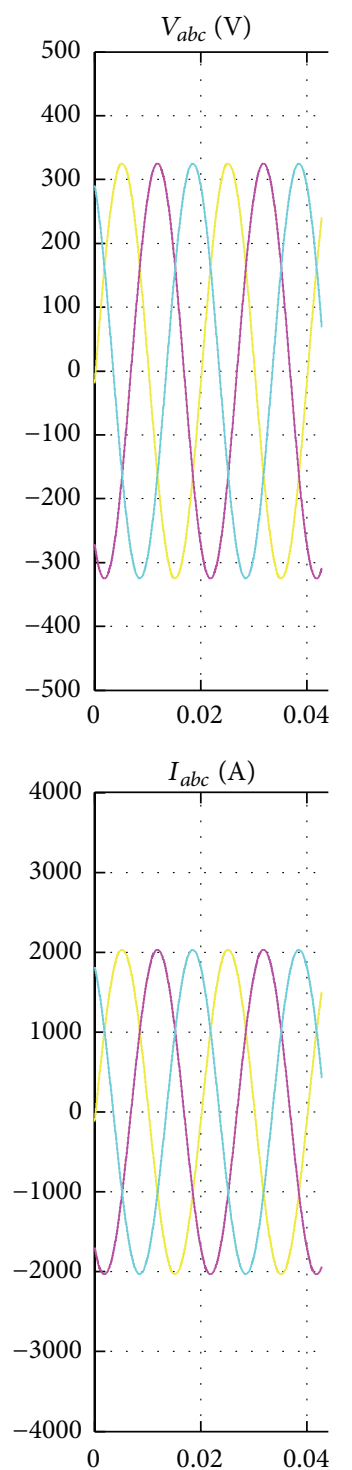

(b) $R_{1}(1 \mathrm{MW})$
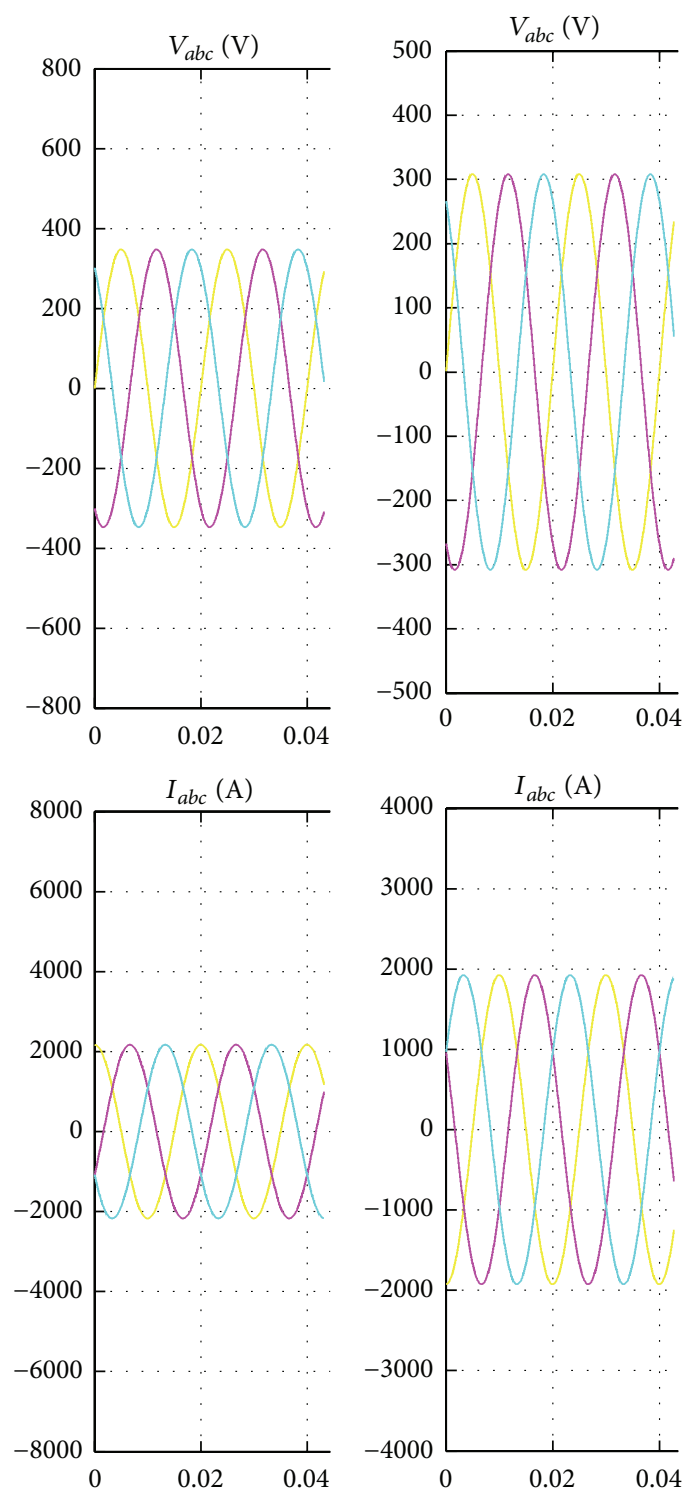

(c) $C_{1}$ (1MVAr)

(d) $L_{1}$ (1MVAr)

FIGURE 4: Diagram voltage $V_{a b c}(\mathrm{~V})$ and current $I_{a b c}(\mathrm{~A})$. 
TABLE 1: Table of the transformers of brochure [13].

\begin{tabular}{|c|c|c|c|c|c|c|c|}
\hline \multirow{2}{*}{$\begin{array}{l}\text { Power } \\
(\mathrm{kVA})\end{array}$} & \multicolumn{2}{|c|}{$\mathrm{HV} / \mathrm{LV}$} & \multirow{2}{*}{$\begin{array}{c}\text { No-load losses } \\
\text { (W) }\end{array}$} & \multirow{2}{*}{$\begin{array}{c}\text { Load losses }\left(75^{\circ} \mathrm{C}\right) \\
(\mathrm{W})\end{array}$} & \multirow{2}{*}{$R_{T}(\Omega)$} & \multirow{2}{*}{$X_{T}(\Omega)$} & \multirow{2}{*}{$Z_{T}(\Omega)$} \\
\hline & $(\mathrm{kV})$ & $(\%)$ & & & & & \\
\hline T1ABB 1000 & $10 / 0.4$ & $6 \%$ & 2000 & 8800 & $1.40 \cdot 10^{-3}$ & $9.5 \cdot 10^{-3}$ & $9.6 e \cdot 10^{-3}$ \\
\hline T2ABB 2000 & $10 / 0.4$ & $6 \%$ & 3500 & 15500 & $0.61 \cdot 10^{-3}$ & $4.76 \cdot 10^{-3}$ & $4.8 \cdot 10^{-3}$ \\
\hline Т3АBВ 3150 & $10 / 0.4$ & $6 \%$ & 5200 & 22600 & $0.34 \cdot 10^{-3}$ & $3.03 \cdot 10^{-3}$ & $3.05 \cdot 10^{-3}$ \\
\hline
\end{tabular}
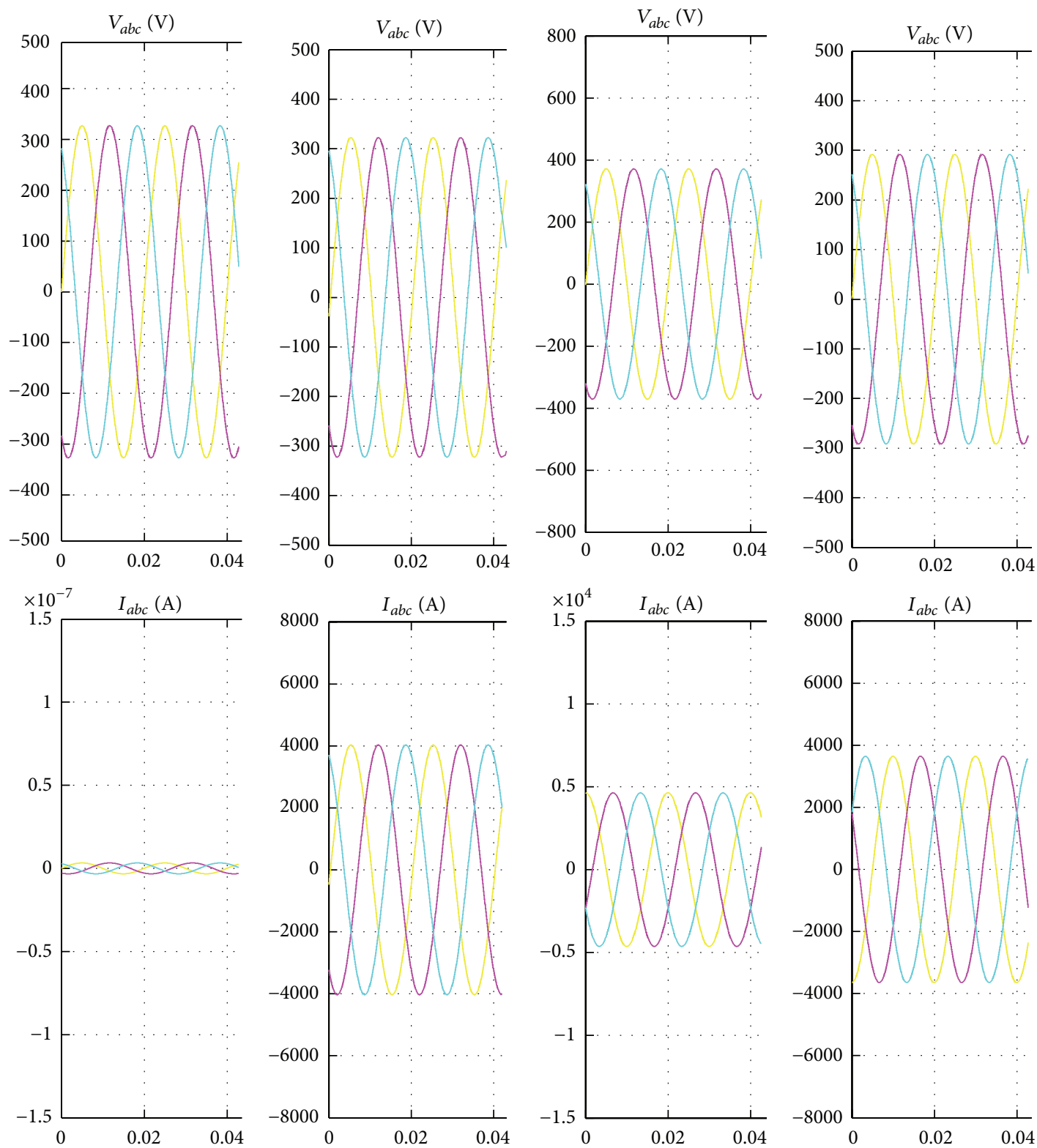

(a) No-load

(b) $R_{2}(2 \mathrm{MW})$

(c) $C_{2}$ (2 MVAr)

(d) $L_{2}(2$ MVAr)

Figure 5: Diagram voltage $V_{a b c}(\mathrm{~V})$ and current $I_{a b c}(\mathrm{~A})$.

(2) Method: apply the formula

$$
\begin{aligned}
& r_{1,2}=\frac{-b \pm \sqrt{b^{2}-4 a c} \text { or }}{2 a} \\
& r_{1,2}=\frac{-b / 2 \pm \sqrt{(b / 2)^{2}-a c}}{a} .
\end{aligned}
$$

And for the form $r^{2}+b_{1} \cdot r+c_{1}=0 \Leftrightarrow r_{1,2}=b_{1} / 2 \pm$ $\sqrt{b_{1}^{2} / 4-c_{1}}$, root characteristic is

$$
r_{1}+r_{2}=-\frac{b}{a}=-b_{1} \text { and } r_{1} \cdot r_{2}=\frac{c}{a}=c_{1} .
$$

Active electric resistance of electrical sources $r$ is due to the physical nature of the real value greater than zero $r>0$ so the 
TABLE 2: Results of values and parameters calculated using the graph-analytical method.

\begin{tabular}{|c|c|c|c|}
\hline Parameters & $\begin{array}{l}\text { T1: } 1[\mathrm{MVA}] \\
|R|=\left|X_{c}\right|=0.16[\Omega]\end{array}$ & $\begin{array}{l}\text { T2: } 2[\mathrm{MVA}] \\
|R|=\left|X_{c}\right|=0.08[\Omega]\end{array}$ & $\begin{array}{l}\text { T2: } 3.15[\mathrm{MVA}] \\
|R|=\left|X_{c}\right|=0.05[\Omega]\end{array}$ \\
\hline$E_{1 m}=E_{2 m}[\mathrm{~V}]$ & 3264 & 3264 & 3264 \\
\hline$E_{1 m}^{2}=E_{2 m}^{2}\left[\mathrm{~V}^{2}\right]$ & 106537 & 106537 & 106537 \\
\hline$V_{1 m}[\mathrm{~V}]$ & 3231 & 3231 & 3232 \\
\hline$V_{1 m}^{2}\left[\mathrm{~V}^{2}\right]$ & 104393.6 & 104329 & 104458 \\
\hline$I_{1 m}[\mathrm{~A}]$ & 2000 & 4000 & 6400 \\
\hline$I_{1 m}^{2}\left[\mathrm{~A}^{2}\right]$ & $4 * 10^{6}$ & $16 * 10^{6}$ & $40.96 * 10^{6}$ \\
\hline$V_{2 m}[\mathrm{~V}]$ & 350 & 350 & 350 \\
\hline$V_{2 m}^{2}\left[\mathrm{~V}^{2}\right]$ & 122500 & 122500 & 122500 \\
\hline$I_{2 m}[\mathrm{~A}]$ & 2200 & 4400 & 7000 \\
\hline$I_{2 m}^{2}\left[\mathrm{~A}^{2}\right]$ & $4.84 * 10^{6}$ & $19.36 * 10^{6}$ & $49 * 10^{6}$ \\
\hline$M\left[\Omega^{2}\right]$ & $5.359 * 10^{-4}$ & $1.340 * 10^{-4}$ & $0.51 * 10^{-4}$ \\
\hline$N\left[\Omega^{2}\right]$ & $-3.298 * 10^{-3}$ & $-0.825 * 10^{-3}$ & $-0.353 * 10^{-3}$ \\
\hline$\frac{M-N}{2}\left[\Omega^{2}\right]$ & $1.914 * 10^{-3}$ & $0.478 * 10^{-3}$ & $0.202 * 10^{-3}$ \\
\hline$\frac{M-N}{2 X_{c}}[\Omega]$ & $11.96 * 10^{-3}$ & $5.99 * 10^{-3}$ & $4.03 * 10^{-3}$ \\
\hline$\left(\frac{M-N}{2 X_{c}}\right)^{2}\left[\Omega^{2}\right]$ & $1.431 * 10^{-4}$ & $0.358 * 10^{-4}$ & $0.163 * 10^{-4}$ \\
\hline$a=1+\left|\frac{R}{X_{c}}\right|^{2}=1+1=2$ & 2 & 2 & 2 \\
\hline$b=2 X_{c}\left(1-\frac{M-N}{2 X_{c}} \frac{1}{X_{c}}\right)\left[\Omega^{2}\right]$ & 0.2961 & 0.148 & 0.0919 \\
\hline$c=\left(\frac{M-N}{2\left|X_{c}\right|}\right)^{2}-M\left[\Omega^{2}\right]$ & $-3.928 * 10^{-4}$ & $-0.981 * 10^{-4}$ & $-0.344 * 10^{-4}$ \\
\hline$r_{2}<0$ not realistic; $r_{1}[\Omega]$ & $1.35-10^{-3}$ & $0.66 * 10^{-3}$ & $0.37 * 10^{-3}$ \\
\hline$r_{1 \mathrm{ABB}}\left[\Omega^{2}\right]$ & $1.40 * 10^{-3}$ & $0.61 * 10^{-3}$ & $0.34 * 10^{-3}$ \\
\hline$x_{2}<$ not realistic $; x_{1}[\Omega]$ & $11.82 * 10^{-3}$ & $5.31 * 10^{-3}$ & $3.66 * 10^{-3}$ \\
\hline$x_{1 \mathrm{ABB}}\left[\Omega^{2}\right]$ & $9.5 * 10^{-3}$ & $4.76 * 10^{-3}$ & $3.03 * 10^{-3}$ \\
\hline
\end{tabular}

characteristic roots of quadratic equations have to be $\operatorname{Re}\left\{r_{1}\right\}>$ $0 ; \operatorname{Re}\left\{r_{2}\right\}>0$. This is possible if $(D \leq 0),\left(4 a c-b^{2}\right) \leq 0$, has two solutions (two real roots or two same roots) and if

$$
\begin{aligned}
& \text { (1) } 0>-\frac{b}{2 a} \text { and } 0>\left[1 \pm \sqrt{1-\frac{4 a c}{b^{2}}}\right] \text { or } \\
& \text { (2) } 0<-\frac{b}{2 a} \text { and } 0<\left[1 \pm \sqrt{1-\frac{4 a c}{b^{2}}}\right] \text {. }
\end{aligned}
$$

Additional condition is that root value must be $\left[1-4 a c / b^{2}\right] \geq$ 0 , where the value for $r$ can stay real value $[r]=\operatorname{Re}$ and because it cannot be imaginary value: $[r] \neq$ Im. As it is $[a>0],[b / 2 a]^{2}>0$, that condition depends on the value relation $[c / a]$ :

$$
\begin{aligned}
{\left[1-\frac{4 a c}{b^{2}}\right] } & =\left[1-\frac{1}{(b / 2 a)^{2}} \frac{c}{a}\right] \geq 0 \\
\left(\frac{b}{2 a}\right)^{2} & \geq\left[\frac{c}{a}\right]
\end{aligned}
$$

If the values are $(b / 2 a)^{2}=[c / a]$ the values of root's quantity are equal to zero and there is one solution for $r_{1}=r=$ $-b / 2 a=\mathrm{Re}-$, the value which in principle means that the value of $b<0$; that is, $b=R\left[2-p / X^{2}\right]<0$. This is possible if $\left[2-p / X^{2}\right]<0$ or with precondition $\left[2<p / X^{2}\right]$. 

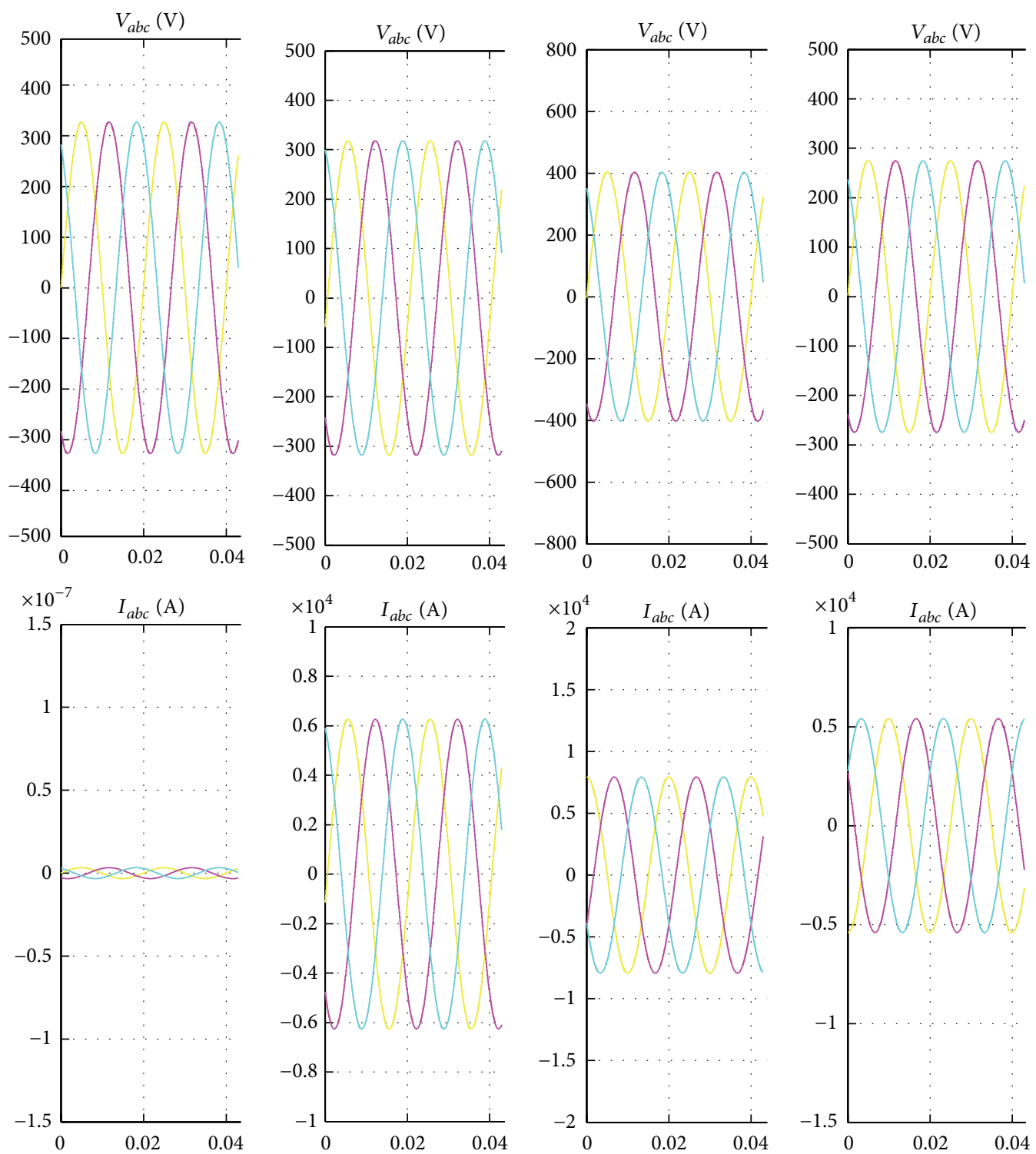

(a) No-load

(b) $R_{3}(3.15 \mathrm{MW})$

(c) $C_{3}(3.15$ MVAr)

(d) $L_{3}(3.15$ MVAr)

FIGURE 6: Diagram voltage $V_{a b c}(\mathrm{~V})$ and current $I_{a b c}(\mathrm{~A})$.

\section{Simulation Results}

In this case, the graph-analytical method for the verification of the simulation method [14], which replaces the measurement method, dry power transformer ABB of coupling Yy, power 1; 2; and 3.15 MVA, and the tests with three measurements for active, for capacitive, and for inductive loads are selected (adapted the program psb3phasesignalseq (Figure 3)) [14].

Data on the three-phase ABB transformers, obtained by experimental procedure in the laboratory, are taken from [13] and shown in Table 1, with the following values:

The paper presents the following obtained values: rated power $[\mathrm{kVA}]$, nominal voltage, connected voltage, or idle running voltage, on primary-higher voltage $\mathrm{HV}(\mathrm{kV}) V_{A}^{\prime}, V_{B}^{\prime}$, and $V_{C}^{\prime}$ and the lower secondary $\operatorname{LV}(\mathrm{kV}) V_{a}^{\prime \prime}, V_{b}^{\prime \prime}$, and $V_{c}^{\prime \prime}$, the impedance value of (\%), idle running losses, and losses of loaded transformer at rated current and current at rated load.

Simulations in MATLAB program (Simulink-Power System, psb3phasesignalseq) on $\mathrm{ABB}$ transformers are derived from $100 \%$ load on $T 1, T 2$, and $T 3$ with $S_{n}=1,2,3.15$ [MVA].

Secondary currents are indicated on diagrams $I_{a}^{\prime \prime}, I_{b}^{\prime \prime}$, and $I_{c}^{\prime \prime}$ and secondary voltages in different load tests with active, reactive capacitive (or inductive) load.

Gained changes of electrical quantities are shown in Figures 4, 5, and 6 .

Diagrams (for harmonic size changes, between maximal and effective values applies relation $I=I_{m} / \sqrt{2}, E=$ $E_{m} / \sqrt{2}$ ) of currents and voltage for a combined test with active and capacitive loads as well as Table 2 which entered all the important values from diagrams and corresponding values are required for the calculation of active resistance 
and reactance of the transformer. From Tables 1 and 2 the deviation can be seen between the results of measuring the value of $R_{T}, X_{T}$, which are stated in the ABB manual and those obtained through simulations and they are different to $20 \%$ for the results of a reactance and up to $5 \%$ for the results of active resistance for all three tested transformer.

Diagrams (for harmonic size changes, between maximal and effective values applies relation $I=I_{m} / \sqrt{2}, E=$ $E_{m} / \sqrt{2}$ ) of currents and voltages for combined test with active and inductive load for all three transformers are shown in the paper, but because of the volume and significant values of diagrams for active resistance and reactance of the transformer the table is not displayed.

\section{Conclusions}

Graph-analytical method can be used not only to determine the active and inductive AC power source parameters but also to determine and analyze the impendence of electrical sources with high frequencies or in a transient process. It should be emphasized that it is better to determine parameters of transformer or source from measuring or simulation test combined with $R$ and $C$ loads that are close to the nominal load, where the errors are minimized. Larger deviations in the measurement or simulating values occur when calculating the reactance, which is natural, because the reactive loads are usually combined with a significant presence of the active component (lower value with capacitive and higher value with inductive loads).

\section{Conflict of Interests}

The authors declare that there is no conflict of interests regarding the publication of this paper.

\section{References}

[1] A. J. Pansini, Electrical Transformers and Power Equipment, The Farmont Press, Lilburn, Ga, USA, 3rd edition, 1999 (Indian).

[2] L. Lawhead, R. Hamilton, and J. Horak, "Three phase transformer winding configurations and differential relay compensation," in Proceedings of the 60th Annual Georgia Tech Protective Relay Conference, Atlanta, Ga, USA, May 2006.

[3] H. Su, G. Jia, and M. Z. Q. Chen, "Semi-global containment control of multi-agent systems with input saturation," IET Control Theory \& Applications, vol. 8, no. 18, pp. 2229-2237, 2014.

[4] H. Su and M. Z. Q. Chen, "Multi-agent containment control with input saturation on switching topologies," IET Control Theory \& Applications, vol. 9, no. 3, pp. 399-409, 2015.

[5] H. Dommel, "Digital computer solution of electromagnetic transients in single-and multiphase networks," IEEE Transactions on Power Apparatus and Systems, vol. 88, no. 4, pp. 388399, 1969.

[6] P. Spalevic, B. Miric, D. Vuckovic, and S. Panic, "Magnetic field of inductive loop-theory and experimental results," Elektronika Ir Elektrotechnika: Elektronika, vol. 99, no. 3, pp. 83-88, 2010.
[7] F. De Leon and A. Semlyen, "Complete transformer model for electro-magnetic transients," IEEE Transactions on Power Delivery, vol. 9, no. 1, pp. 231-239, 1994.

[8] N. Markovic, S. Bjelic, U. Jaksic, and Z. Bogicevic, "Graphical zero-sequence cut-offs method of determining of fault to earth in electrical lines," in Proceedings of the 9th Symposium on Neural Network Applications in Electrical Engineering (NEUREL '08), pp. 73-76, Belgrade, Serbia, September 2008.

[9] M. Fatima, R. Youcef, H. Assia, H. Habib, and B. Abdelber, "The non linear controller for terminal voltage and power angle of power systems," ACTA Polytechnica Hungarica, vol. 10, no. 8, pp. 205-218, 2013.

[10] Y. Shibuya and S. Fujita, "High frequency model and transient response of transformer windings," in Proceedings of the IEEE/PES Transmission and Distribution Conference and Exhibition: Asia Pacific, vol. 3, pp. 1839-1844, IEEE, Yokohama, Japan, October 2002.

[11] L. L. Grigzby, "Transient voltage response of coils and windings," in Response of Coils and Windings, vol. 10, CRC Press LLC; Auburn University, Auburn, Ala, USA, 2001.

[12] E. P. Dick and C. C. Erven, "Transformer diagnostic testing by frequuency response analysis," IEEE Transactions on Power Apparatus and Systems, vol. PAS-97, no. 6, pp. 2144-2153, 1978.

[13] ABB Transformers Power Technologies Division, 2015, http:// www.abb.com/transformers.

[14] S. Bjelić and Z. Bogićević, "Computer simulation of theoretical model of electromagnetic transient processes in power transformers," International Journal of Information Technology and Computer Science, vol. 6, no. 1, pp. 1-12, 2014. 


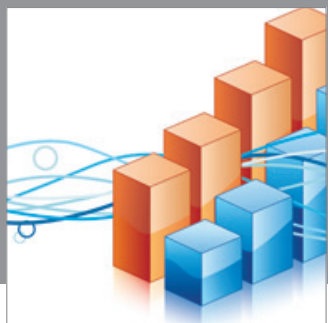

Advances in

Operations Research

mansans

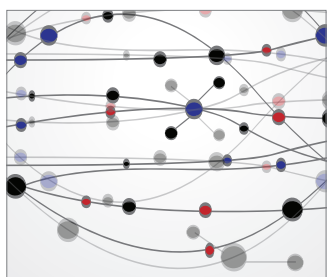

The Scientific World Journal
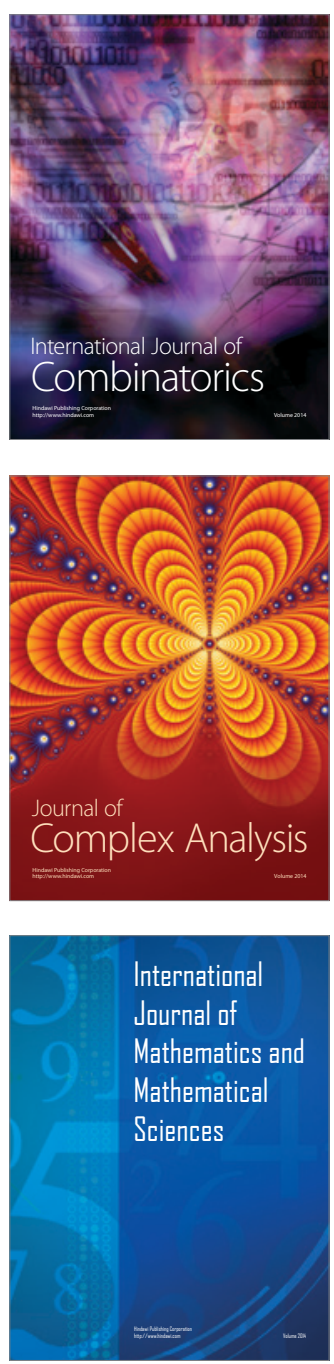
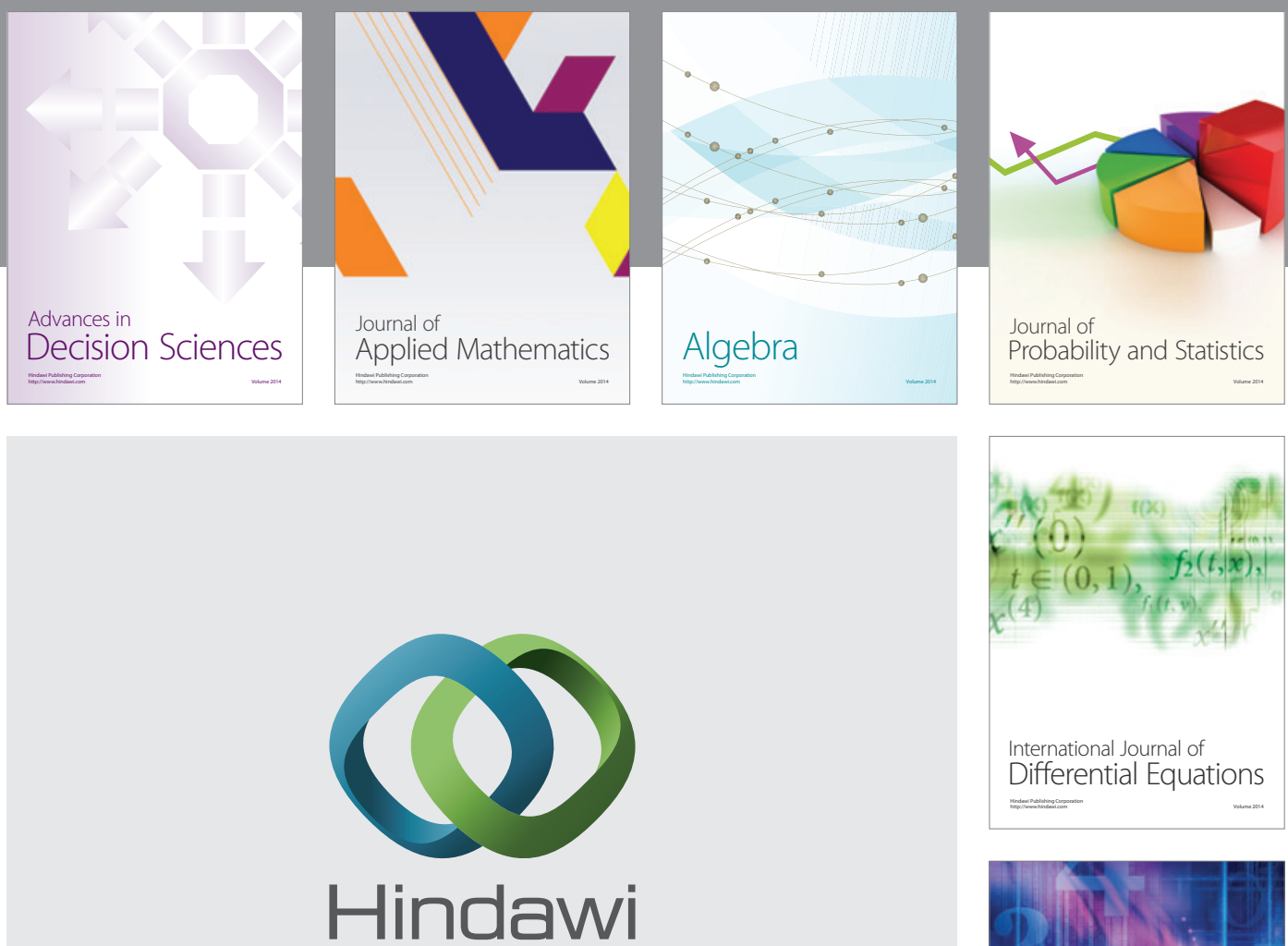

Submit your manuscripts at http://www.hindawi.com
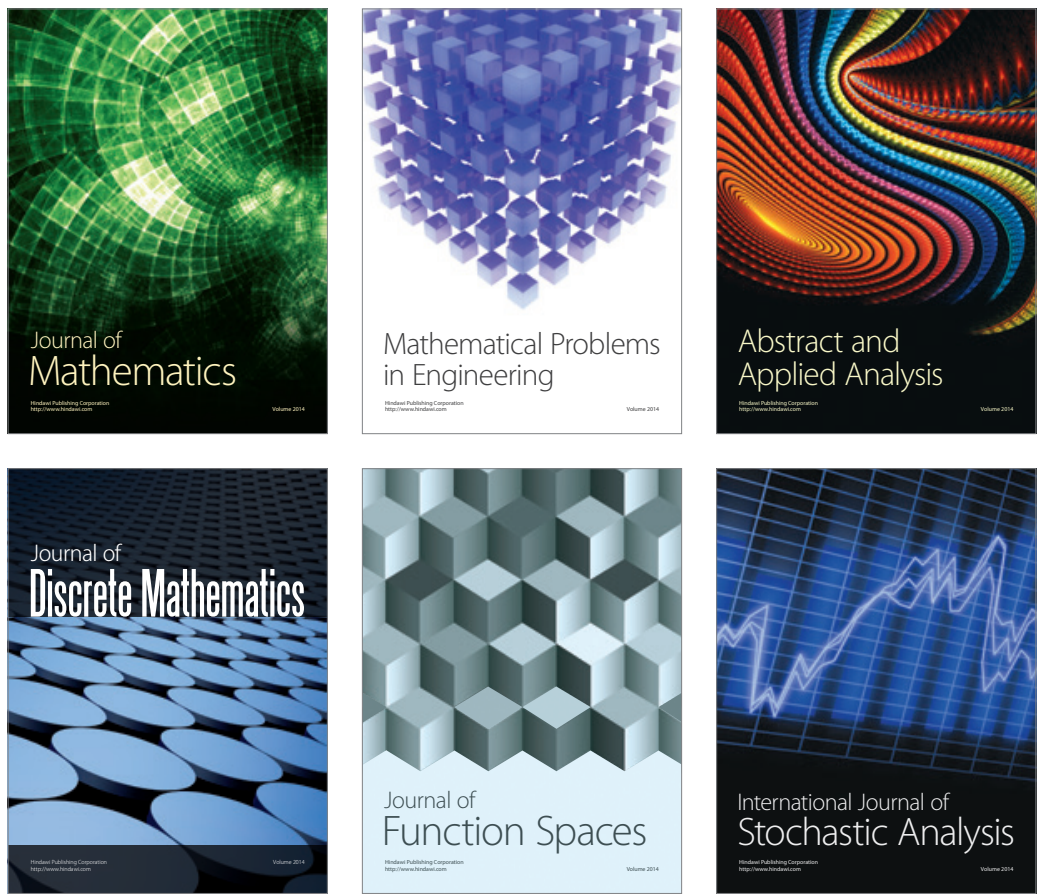

Journal of

Function Spaces

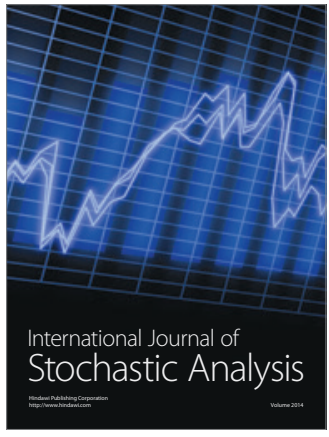

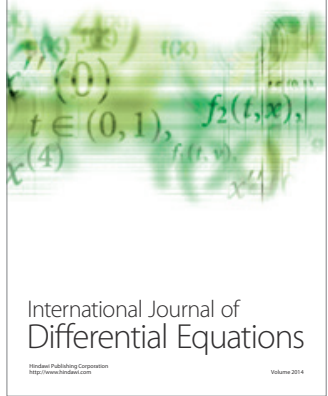
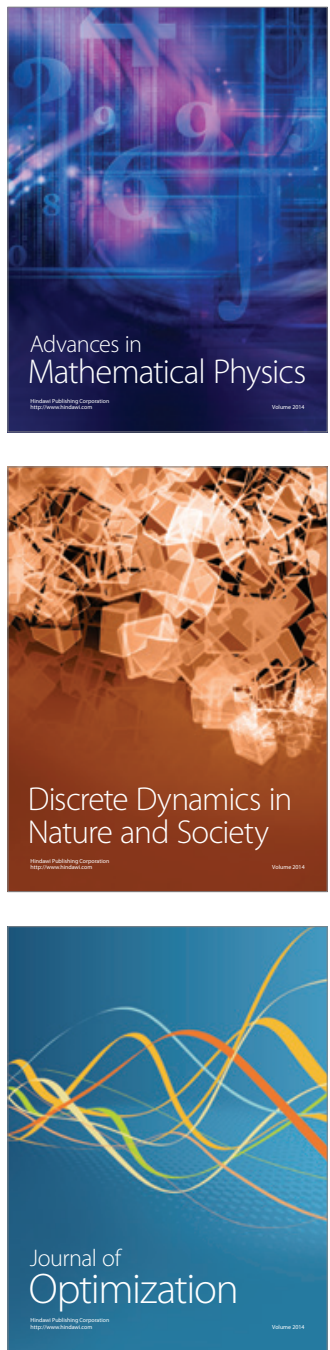